\title{
Reproductive Health Rights: A Case Study in India
}

\author{
Abhilasha Mittal \\ Jindal Global Law School, O. P. Jindal Global University, Sonipat, India
}

\section{Email address:}

16jgls-amittal@jgu.edu.in

\section{To cite this article:}

Abhilasha Mittal. Reproductive Health Rights: A Case Study in India. World Journal of Public Health. Vol. 3, No. 3, 2018, pp. 99-104. doi: 10.11648/j.wjph.20180303.15

Received: August 8, 2018; Accepted: September 3, 2018; Published: September 27, 2018

\begin{abstract}
Reproductive rights are seen as dynamic rights that can vary according to the evolution of the society. Although the World Health Organization gives a standard definition to explain this set of rights, there is still scope for wider interpretation of terms "mental, social and physical well being". This paper, therefore, attempts to understand and interpret the scope via a list certain factors or indicators that could be applied to determine the standard of reproductive health in a country. The indicators for this paper have been attempted to be chosen in such a way that all the intricate factors are also accounted for under the broad headings. The paper also aims to apply these indicators on the availability of reproductive rights and its standards as given to women in India through various reports and case studies. This analysis will not only reveal the status of these rights in practice but also reveal one of the main reasons for the non-availability i.e. poverty and lack of access. The paper, in its final portion, concludes by recommending the state to enhance their policies with respect to these rights in order to ensure better health for not only improving the health of women, but to also improve the health of infants and men who are directly or indirectly affected by the same.
\end{abstract}

Keywords: Reproductive Rights, Dynamic, Indicators, India

\section{Introduction}

Human rights are one of the tools to ensure effective and uplifting governance of the people. It can be observed that reproductive health is an important part of basic human rights because it not only affects the health of the mother and child but can indirectly affect the mental health of the man as well. It, therefore, becomes necessary that reproductive health is recognized as a human right. This would obligate the countries to respect, protect and fulfill this human right. ${ }^{1}$ The right, however, is not recognized as a human right in the international covenants directly but does become an indirect right under right to health ${ }^{2}$ of Universal Declaration of

1 CESCR General Comment no. 12: The Right to Adequate Food (Art. 11) 2 Article 25 of UDHR - (1) Everyone has the right to a standard of living adequate for the health and well-being of himself and of his family, including food, clothing, housing and medical care and necessary social services, and the right to security in the event of unemployment, sickness, disability, widowhood, old age or other lack of livelihood in circumstances beyond his control.

(2) Motherhood and childhood are entitled to special care and assistance. All children, whether born in or out of wedlock, shall enjoy the same social protection.
Human Rights and Article 12(2) (a) ${ }^{3}$ of the International Covenant on Economic, Social and Cultural Rights.

Reproductive health in simple words can be defined as the health of a woman before and after the reproduction process. World Health Organization within its framework defines reproductive health as a situation in which an individual has complete mental, social and physical well being rather than only focusing on absence of freedom of reproductive processes and diseases. 4 However, the definition is applicable only in the framework of WHO and therefore the definition keeps evolving with the passage of time. Furthermore, the definition has been worded in a broad sense and therefore can be open to interpretations. It could mean that people have the ability to reproduce and the ability to regulate their fertility. ${ }^{5}[1]$ It could also include the ability to

3 Article 12(2)(a) of International Covenant on Economic, Social and Cultural Rights - 2. The steps to be taken by the States Parties to the present Covenant to achieve the full realization of this right shall include those necessary for:

(a) The provision for the reduction of the stillbirth-rate and of infant mortality and for the healthy development of the child;

4 World Health Organization, Reproductive Health, http://www.who.int/topics/reproductive_health/en/

5 Mahmoud F. Fathalla, Promotion of Research inhuman Reproduction: Global 
practice and enjoy sexual relationships along with the ability to reproduce and regulate their fertility. ${ }^{6}$ [2] There are various social and economic factors that determine the decision of a couple to plan a family. Therefore the fundamental issues that arise while making this decision are autonomy, privacy and agency that the woman should have with respect to her health choices. $^{7}[3]$

The aim of this paper is to understand the dynamic nature of reproductive health and define the scope of this right by laying down certain indicators. It attempts to link the right to the broader human right of right to health recognized under the Universal Declaration of Rights. The paper further applies the indicators chosen to the situation of women with respect to reproductive health in India. It tries to apply these international standards on Indian laws with respect to right to reproductive health that would help us understand the standard of reproductive healthcare provided to women in India.

There are various indicators ${ }^{8}$ [4] to assess the standard of reproductive health provided to the mother before and after the pregnancy. These indicators, in totality, help the investigators understand whether the mother and child are healthy. For the purposes of this paper, six indicators have been chosen to understand and define the scope of reproductive health rights.

Maternal Mortality rates are one of the main indicators to depict the standard of the issue in question. The inadequate amount of nutrients in the woman when she is pregnant, along with the increasing cases of complications in the mother leads to death of about 1500 women almost everyday. ${ }^{9}$ This rate can be reduces by increasing the access to skilled health personnel during delivery for the mothers, establishing more number of birth hospitals and providing adequate training to midwives for home deliveries. Sri Lanka, for example, has taken these measures to reduce maternal mortality rates by over $90 \% .^{10}$

The second indicator is the percentage of population that has access to reproductive health services. In various developing countries, the number of skilled health personnel is not enough in order to attend all the deliveries that take place. Therefore, the mothers don't have access to proper healthcare during delivery due to which they are prone to complications more than the mothers who have access to skilled health personnel. If the countries are able to launch training programs for the health personnel in order to educate

Needs and Perspectives, 3 HUM.

6 Mahmoud F. Fathalla, Reproductive Health: A Global Overview, 626 Annals N.Y. Acad. Sci. 1,1 (1991).

7 Ruth Bader Ginsburg, Essay, Some Thoughts on Autonomy and Equality in Relation to Roe v. Wade, 63 N.C. L., Rev. 375, 383 (1985)

8 Lance Gable, Reproductive Health as a Human Right, Wayne State University Law School, Legal Studies Research Paper Series no. 10-20.

9 WHO, Making Pregnancy Safer: Maternal Mortality, http://www.who.int/making_pregnancy_safer/topics/maternal_mortality/en/index. html.

10 NAT'L COUNCIL OF ECON. DEV. OF SRI LANKA, MILLENIUM DEVELOPMENT GOALS COUNTRY REPORT 2005: SRI LANKA 61-64 (2005), http://www.mdg.lk/inpages/mdg_reports/2005/mdg_report_2005.htm. them about the pregnancy methods, more number of women would have access to the former thereby ensuring a higher rate of reproductive health in the country.

The third indicator is family planning services. There are various countries that have put restrictions and limitations on the access to contraceptives. A report issued by United Nations Population Fund stated that there are 200 million women across the globe who are trying to prevent or delay pregnancy but don't have access to effective contraceptives. ${ }^{11}$ These limitations not only lead to complications in health of the woman and the baby due to unwanted pregnancies but also increase the probability of sexually transmitted problems like HIV. The countries should therefore try to avoid putting limitations on access to contraceptives for the development of reproductive health.

The fourth indicator is the abortion services. Due to unwanted and teenage pregnancies that happen because of lack of proper access to contraceptives, there are many women who are prone to get unsafe abortions. This leads to many issues like not being able to deliver in future, excessive internal bleeding, infections and even death. The United Nations has also reported that an estimated of 20 million women per year go through unsafe pregnancies in the least developed countries that results in 68,000 maternal deaths every year. $^{12}$

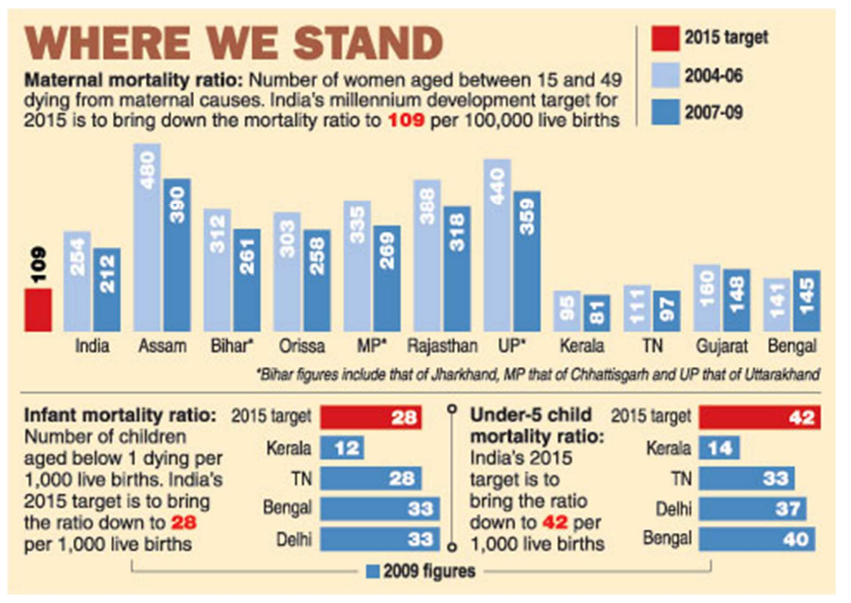

Figure 1. Maternal Deaths caused by unsafe abortion in South Asia.

Source: 'Maternal Mortality Rate - Subject | Prepare IAS'

http://prepareias.in/subject/gs/indian-economy-/maternal-mortality-rate

The fifth indicator is the prevalence of female genital mutilation. There are still many parts in Africa and Middle East where genital mutilation of young girls and women remains a widespread ritual. ${ }^{13}$ [5] This practice has serious reproductive health related consequences because the women and young girls become more prone to infections in the

11 United Nations Population Fund (UNFPA, A Global Need for Family Planning (2008), http://www.unfpa.org/rh/planning/mediakit/docs/new_docs/sheet1english.pdfa

12 United Nations Population Fund, Fact Sheet: Motherhood and Human Rights, (2009), http://unfpa.org/public/cache/offonce/factsheets/pid/3851\#contraception.

13 Lewis Hope, Female Genital Mutilation and Female Genital Cutting, in 2 Encyclopedia of Human Rights 200, 201 (David P. Forsythe ed., 2009) 
reproductive tract, prolonged or obstructed childbirth and infertility. (Hope 2009) This practice is in itself discriminatory against women thereby violating not only right to equality and dignity which are basic human rights but also right to health.

The sixth and another crucial indicator is the sexually transmitted diseases. Due to the limited access to effective contraception and lack of awareness about these sexually transmitted diseases, the number of cases about these diseases is increasing which adversely affects a woman's reproductive health. It not only gives rise to complications in pregnancy but also tends to risk the life of the baby that might lead to stillbirths or miscarriage.

\section{Case Study: Reproductive Health Across the Globe}

There have been several cases across the globe, which have reiterated the importance of reproductive health through various issues like abortion, contraception and other legal restrictions and barriers. In Planned Parenthood of Se. Pa v. Casey ${ }^{14}$, the Supreme Court of U.S. decided that the it is essential to give the women the right to decide when, whether and how to bear children to provide them the potential to participate equally in economic and social aspects of the country.

The Case of VO v. France ${ }^{15}$ case, which involved the negligence of a doctor leading to rupturing of a pregnant woman's amniotic sac, was decided in the European Court of Human Rights. The pregnant woman lost her unborn fetus. The court stated that Article 2 of the Convention for the Protection of Human Rights and Fundamental Freedoms has been violated by the responding state because every woman has a right to adequate reproductive healthcare and since the woman lost her child because of the doctor's negligence, the state should take the responsibility.

With relation to reproductive health within India, there have been several cases that have challenged the nonavailability and inadequate access of reproductive health rights to women across the entire country. For example, in the case of Kalyani Meena v. Union of India \& Ors, the Jharkhand High Court stated that the government should take responsibility for the increasing number of maternal deaths in the state of Jharkhand because of the non-implementation of various governmental policies that have been launched. ${ }^{16}$

Another case is CHARM v. State of Bihar and Ors. ${ }^{17}$ in which the Center's partner, Human Rights Law Network, filed public interest litigation about the denials to woman for the maternal health care by the state of Bihar in the Patna
High Court. As the previous case, the Court ordered the state to submit an expense report accounting for every rupee under the various state policies that provide maternal healthcare to woman. The court, through this order, reaffirmed the state's obligation to respect, protect and fulfill the right to access to reproductive health to its citizens.

A case study on a woman named Sumitra Devi ${ }^{18}$ reveals the poor quality of care Primary Health Centers provide. The facts of the case disclose that the woman had gone to the hospital due to continuous labor pains and was given fourteen injections in a span of four hours without justifications and in the absence of a doctor. When her pain increased and she began screaming, she was slapped. A few minutes later, her body was completely cold which meant she had passed away.

A public interest litigation, Forum for Fact Finding Documentation and Advocacy v. Union of India ${ }^{19}$ was also filed in the Supreme Court against the ill practice of child marriage that was being performed in states like Rajasthan and Madhya Pradesh at a large scale. This is related to reproductive health because young girls aged 6-14 years were getting pregnant and suffering from early pregnancy issues like maternal and infant mortalities.

It is a known fact that the International Human Rights law safeguards the rights of pregnant women to access voluntary sterilization programs free of coercion and discrimination. Therefore, in Ramakant Rai v. Union of India ${ }^{20}$, the Supreme Court ordered the state governments to ensure appropriate steps on an urgent basis in order to improve access of women to voluntary sterilization programs. This decision was in response to the issue raised in this case about abusive and coercive practices of the government in these voluntary sterilization programs.

\section{Result}

Through all these cases, it can be concluded that the courts across the globe and specifically India have recognized the need for recognition and assurance of right to reproductive health to women; yet, the governments of the states are unable to guarantee this right. In the context of India, there are many programmes and initiatives started by the government like National Rural Health Mission and Janani Suraksha Yojana, however, there have been many implementation challenges that were faced by the programme. This was due to lack of institutional preparedness, not enough training of health personnel dealing with reproductive health and corruption within the government and the health system. 21

\footnotetext{
14505 U.S. 833, $846(1992)$

15 Case of VO v. France, Centre for Reproductive Rights, https://www.reproductiverights.org/case/vo-v-france-european-court-of-humanrights

16 Kalyani Meena v. Union of India \& Ors, Centre for Reproductive Rights, https://www.reproductiverights.org/case/kalyani-meena-v-union-of-india-ors 17 C.W.J.C. No. $7650 / 2011$
}

18 Sahayog, Case Study: Sumitra Devi, (2007).

19 W.P. (Civ.) No. 212 of 2003 (Supreme Court of India, Apr. 25, 2003)

20 W.P (C) No 209 of 2003

21 Reviewing Two Years of NRHM, Citizens Report, October 2007. 


\section{Discussion: Reproductive Health's Status in India Based on the Indicators}

The human rights principles have been challenged on the reality of the promise to make motherhood safe. These rights have been recognized nationally and internationally and therefore they should be respected and ensured to the best possibility to the entire population of the world. ${ }^{22}$ [6] Reproductive rights have been recognized as basic human rights in the International Conference on Population and Development as the right of all individuals and couples to determine the number and spacing of their children in a free and responsible way. ${ }^{23}$ However, in India, this basic human right is not being strictly ensured. It has been observed that more number of women die in India because of lack of adequate maternal healthcare than anywhere else across the globe.

The United Nations agencies have reported that approximately $117,000^{24}$ deaths happen in India due to pregnancy related issues. This number adds up to almost one quarter of the entire world's annual maternal deaths. Reproductive rights have been recognized as basic human rights in the International Conference on Population and Development as the right of all individuals and couples to determine the number and spacing of their children in a free and responsible way. ${ }^{25}$ [7] These deaths are caused by multiple factors, the first one being medical inability. Medical inability can be further divided into direct causes like hemorrhage, hypertensive disorders related to pregnancy or indirect causes like malaria, HIV/AIDS or anemia. ${ }^{26}$ These causes are not unknown to Indian population and hence the high maternal mortality rate can be explained.

The second root cause is malnutrition ${ }^{27}$ [8] of women before and after the pregnancy. It is a widely known fact that $70 \%$ of the Indian population lives below poverty line and do not have access to proper quality food. This percentage of population therefore, do not have adequate nutrition and nourishment for themselves and their babies in their body due to which they are more prone to maternal deaths. Furthermore, the life of the baby also becomes prone to malnourishment, mental disorders and physical disabilities.

22 Rebecca Cook and Bernard Dickens, Advancing Safe Motherhood Through Human Rights 6 (World Health Organization 2001)

23 Programme of Action of the International Conference on Population and Development, Cairo, Egypt, Sept. 5-13, (1994).

24 Joint Press Release, United Nations Population Fund, Maternal Mortality Declining in Middle-income Countries; Women Still Die in Pregnancy and Childbirth in Low-income Countries (Oct. 12 2007).

25 Programme of Action of the International Conference on Population and Development, Cairo, Egypt, Sept. 5-13, (1994).

26 UNFPA, Emergency Obstetric Care: Checklist for Planners, 1 (2002)

27 Center for Reproductive Rights, Maternal Mortality in India: Using

International and Constitutional Law to Promote Accountability and Change
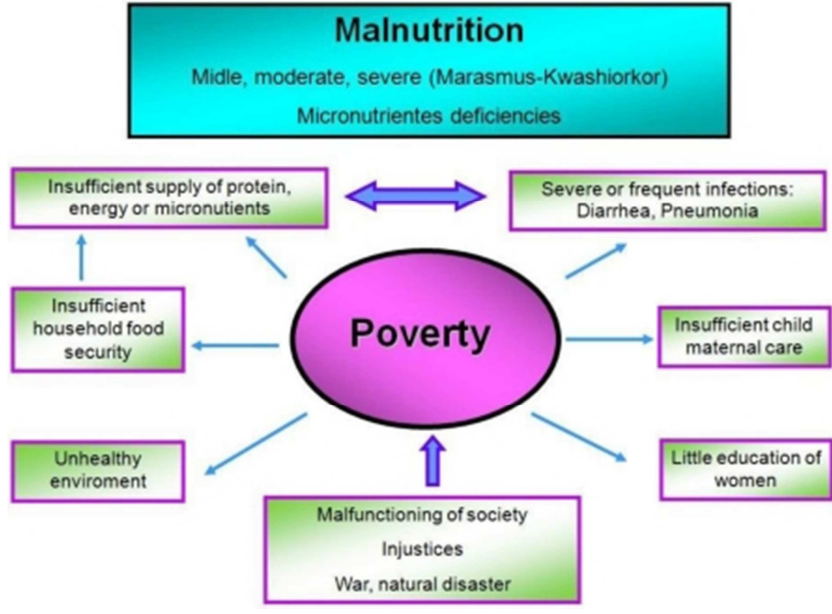

Figure 2. Reasons for malnutrition.

Source: Leonor Rodríguez, L \& Cervantes, Elsa \& Ortiz-Muñiz, Rocío. (2011). Malnutrition and Gastrointestinal and Respiratory Infections in Children: A Public Health Problem. International Journal of Environmental Research and Public Health. 8. 1174-205. 10.3390/ijerph8041174.

The insufficient information couples and women have access to with respect to family planning can also indicate the problem of inadequate reproductive health rights. The UNFPA ${ }^{28}[9]$ has reported that one in every death that happen can be reduced if all women have access to contraceptives in India. The NFHS-3 has revealed that $21 \%$ of all pregnancies are unwanted and unplanned even though the child might be alive at birth. ${ }^{29}[10]$ Furthermore, very few women have access to contraception in the first place due to which they are prone to unwanted pregnancies and sexually transmitted diseases like HIV/AIDS.

Due to corruption and loopholes in the laws made to make an abortion center legal, about $18 \%$ of women go through unsafe abortions which happen in non-governmental hospitals or centers. (NFHS-3 2007) Most of the time the conditions of the hospitals or centers are unhygienic or the doctors performing the abortion are not skilled and trained enough causing several direct and indirect consequences. These women are not able to access proper abortion services because of lack of information and awareness, inadequate number of doctors to perform trained abortion, poor access to abortion centers and several more. These reasons also lead to increasing maternal mortality rates thereby denying reproductive rights, right to health and right to life to the women.

The Indian traditions of child marriage also add to the number of deaths of women before or after pregnancy. Almost $50 \%$ of the country, according to NFHS-3 (NFHS-3 2007), practices this tradition and girls are married under the age of 18. It can be observed that those states who have high rates of child marriage also have high rates of mortality rates of women before and after pregnancy because young girls are not able to carry their babies at such a young age when their bodies are still developing.

28 UNFPA, Reducing Risks by Offering Contraceptive Services.

29 NFHS-3, International Institute for Population Sciences and Macro International, National Family Health Survey 2005-06: India, Volume 1, (2007). 


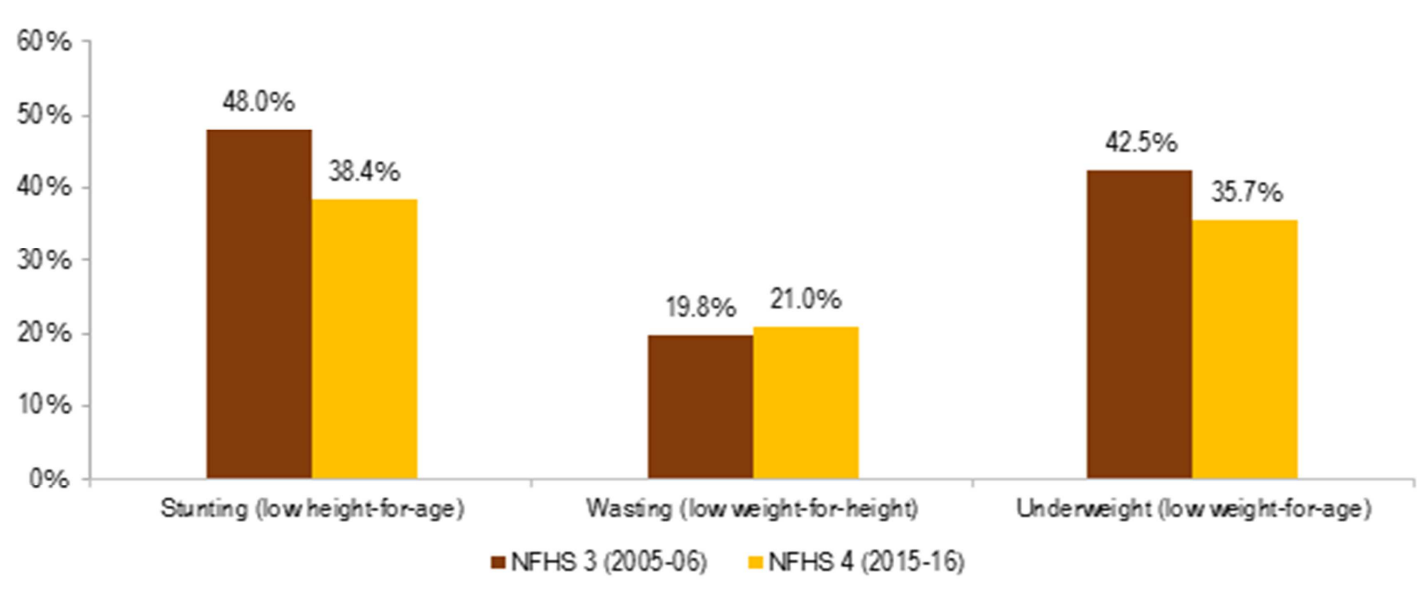

Source: National Family Health Survey 3 \& 4; PRS.

Figure 3. Percentage of children who are stunned, wasted and underweight because of malnutrition.

\section{Girls \& Boys Married Below Legal Age}
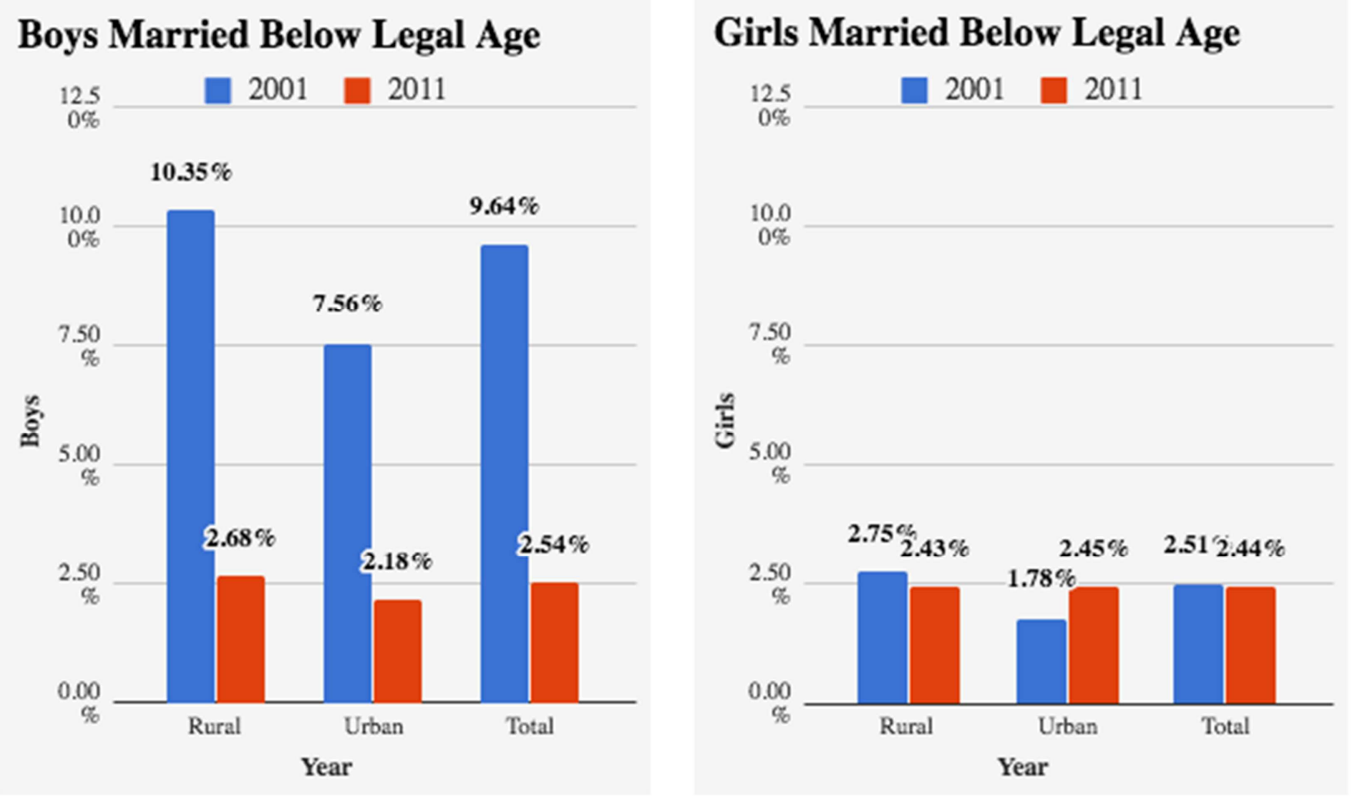

Source: 'Child Marriages Rising in Urban India, Declining in Rural' (The Wire) https://thewire.in/gender/child-marriage-urban-india

Figure 4. Child Marriages of Boys and Girls comparison between the censuses in India.

The problem of sexually transmitted diseases is further an added disadvantage for a pregnant woman because she is either denied treatment or is discriminated against and hence doesn't receive proper reproductive care. ${ }^{30}$ These women are prone to higher risks of infections because they are theoretically forced to give birth in unhygienic conditions. This treatment of such women not only violates their right to reproductive health and right to health but also violates their right to life, right to freedom from cruel, inhuman and degrading treatment and right to equality and nondiscrimination.

30 Human Rights Law Network, Gita Bai, (2007).

\section{Conclusion}

It can be concluded that all the indicators that have been discussed, when applied to the situation of India, depicts that India is really lagging behind in guaranteeing right to health and reproductive rights as basic fundamental rights. The standard of reproductive health that is being provided in India to its women citizens is not enough to ensure right to life as a fundamental right and therefore the state needs to improve the implementation of its policies. The state should also create new policies in order to ensure adequate training to doctors performing pre and post pregnancy practices. The lack of accessibility to the lower strata of people is affecting the health of not only the women pre and post pregnancy but 
also increasing the infant mortality rates and malnourishment. Hence, India should try its best to provide these basic human rights to its citizens so that women can also live their life with dignity.

\section{References}

[1] Mahmoud F. Fathalla, Promotion of Research inhuman Reproduction: Global Needs and Perspectives, 3 HUM.

[2] Mahmoud F. Fathalla, Reproductive Health: A Global Overview, 626 Annals N.Y. Acad. Sci. 1,1 (1991).

[3] Ruth Bader Ginsburg, Essay, Some Thoughts on Autonomy and Equality in Relation to Roe v. Wade, 63 N.C. L., Rev. 375, $383(1985)$

[4] Lance Gable, Reproductive Health as a Human Right, Wayne State University Law School, Legal Studies Research Paper Series no. 10-20.
[5] Lewis Hope, Female Genital Mutilation and Female Genital Cutting, in 2 Encyclopedia of Human Rights 200, 201 (David P. Forsythe ed., 2009).

[6] Rebecca Cook and Bernard Dickens, Advancing Safe Motherhood Through Human Rights 6 (World Health Organization 2001).

[7] Programme of Action of the International Conference on Population and Development, Cairo, Egypt, Sept. 5-13, (1994).

[8] Center for Reproductive Rights, Maternal Mortality in India: Using International and Constitutional Law to Promote Accountability and Change.

[9] UNFPA, Reducing Risks by Offering Contraceptive Services.

[10] NFHS-3, International Institute for Population Sciences and Macro International, National Family Health Survey 2005-06: India, Volume 1, (2007). 